\title{
The Magnetic Diagnostic Set for ITER
}

\author{
Duccio Testa, M. Toussaint, R. Chavan, J. Guterl, J. B. Lister, J.-M. Moret, A. Perez, F. Sanchez, B. Schaller, \\ G. Tonetti, A. Encheva, G. Vayakis, C. Walker, Y. Fournier, T. Maeder, A. Le-Luyer, Ph. Moreau, \\ G. Chitarin, E. Alessi, R. S. Delogu, A. Gallo, N. Marconato, S. Peruzzo, M. Preindl, \\ H. Carfantan, E. Hodgson, J. Romero, R. Vila, B. Brichard, and L. Vermeeren
}

\begin{abstract}
This paper presents the multiple set of requirements for the ITER magnetic diagnostic systems and the current status of the various R\&D activities performed by the EU partners.
\end{abstract}

Index Terms - ITER, magnetic diagnostic system.

\section{INTRODUCTION}

$\mathbf{E}$ FFICIENT commissioning and successful operation of ITER require an extensive and reliable set of magnetic diagnostics. According to international agreement, the magnetic diagnostic set is to be provided to ITER as a EURATOM contribution via in-kind procurement through Fusion for Energy (the European Domestic Agency for ITER). These systems need to satisfy multiple requirements: safety and machine protection, real-time plasma control, measurement and stabilization of magnetohydrodynamic (MHD) modes, postpulse equilibrium reconstruction, and physics diagnostic functions. The proposed magnetic diagnostic systems include measurements of fields,

Manuscript received June 26, 2009; revised October 6, 2009. First published December 31, 2009; current version published March 10, 2010. This work was supported in part by the European Communities under Contracts of Association and in part by the national funding of the participating associations. This paper is an extended version of a contribution presented at the SOFE 2009 Conference.

D. Testa, M. Toussaint, R. Chavan, J. Guterl, J. B. Lister, J.-M. Moret, A. Perez, F. Sanchez, B. Schaller, and G. Tonetti are with the Centre de Recherches en Physique des Plasmas, Association EURATOM-Confédération Suisse, Ecole Polytechnique Fédérale de Lausanne, 1015 Lausanne, Switzerland (e-mail: duccio.testa@epfl.ch).

A. Encheva, G. Vayakis, and C. Walker are with the ITER Organization, 13108 Saint-Paul-lez-Durance, France.

Y. Fournier and T. Maeder are with the Laboratoire de Production Microtechnique, Ecole Polytechnique Fédérale de Lausanne, 1015 Lausanne, Switzerland.

A. Le-Luyer and $\mathrm{Ph}$. Moreau are with the Association Euratom CEA, CEA/DSM/IRFM, Cadarache, 13108 Saint-Paul-lez-Durance, France.

G. Chitarin and A. Gallo are with the Consorzio RFX-Association EURATOM-ENEA, 35127 Padova, Italy, and also with the Dipartimento di Tecnica e Gestione dei Sistemi Industriali, Università di Padova, 36100 Vicenza, Italy.

E. Alessi and M. Preindl are with the Consorzio RFX-Association EURATOM-ENEA, 35127 Padova, Italy, and also with the Dipartimento di Ingegneria Elettrica, University of Padova, 36100 Padova, Italy.

R. S. Delogu, N. Marconato, and S. Peruzzo are with the Consorzio RFX-Association EURATOM-ENEA, 35127 Padova, Italy.

H. Carfantan is with the Laboratoire d'Astrophysique de Toulouse-Tarbes, Centre National de la Recherche Scientifique, 31400 Toulouse, France.

E. Hodgson, J. Romero, and R. Vila are with the CIEMAT Association EURATOM, 28040 Madrid, Spain.

B. Brichard and L. Vermeeren are with the Centre d'Etude de l'Energie Nucléaire, SCK-CEN, 2400 Mol, Belgium.

Color versions of one or more of the figures in this paper are available online at http://ieeexplore.ieee.org.

Digital Object Identifier 10.1109/TPS.2009.2037226 fluxes, plasma current, and diamagnetic flux made inside and outside the vacuum vessel. A set of safety important component (SIC) plasma current measurements has recently been considered to complete this set, although no final decision has been made. This system is a standard for all operating tokamaks, and the spread of knowledge is very abundant [1]. However, there are specific challenges related to developing such diagnostic systems to provide all the required functions for ITER: gamma, neutron, radiation, and thermal effects on the in-vessel sensors and cabling; long-pulse integration and drift compensation for the exvessel data acquisition electronics; and long-term access-free reliability for maintenance. Additional noninductive steady-state diagnostics are being studied to meet the challenges associated with the long-pulse operation for inductive sensors.

This paper is an extended version of the proceedings of the SOFE 2009 Conference [2]: in this paper, the present design of the ITER magnetic diagnostic system is summarized, and the R\&D work underway to meet some of the challenges indicated earlier is also outlined. This paper is organized as follows. In Section I, we briefly review the current measurement requirements for the magnetic diagnostic set in ITER. Section II gives an overview of the challenges to these systems which are novel and specific to ITER. In Section III, we review the currently proposed implementation for the magnetic diagnostic systems in ITER. In Section IV, we briefly review the risk analysis for this diagnostic system so as to show the complexity of the work in hand. To understand how such complexity is tackled, and using the high-frequency (HF) magnetic sensors as a practical example, we then also include in Section IV a more "project-management"-oriented overview of the currently foreseen planning activities, which are intended in dealing with and mitigating the risks associated to the complexity of the ITER environment. Finally, in Section V, we present a summary and draw some conclusions toward future activities.

\section{Measurement Requirements for the Magnetic DiAGNOSTIC SYSTEMS IN ITER}

The detailed requirements for the magnetic sensors needed to meet the purposes of this diagnostic system in ITER are well established [3], [4] and are briefly summarized in Table I together with the main risks that could prevent the achieving of the intended goals. These requirements cover measurement capabilities, diagnostic functionalities, and safety and are overviewed in the next sections. 
TABLE I

iter Magnetic Diagnostic Set: For Each Technique, the Rationale Behind Its Use and the Primary Risks in Achieving the Intended Measurement Performance Are Summarized

\begin{tabular}{|c|c|c|}
\hline measurement type & number of sensor & rationale and main risks \\
\hline \multirow{3}{*}{$\begin{array}{l}\text { in-vessel inductive probes for } \\
\text { equilibrium reconstruction and } \\
\text { real-time control }\end{array}$} & $150 \times$ Btangential & \multirow{3}{*}{$\begin{array}{l}\text { current standard method } \\
\text { long-term failure, drifts, 3D } \\
\text { effects (ferritic inserts, TBM), } \\
\text { image currents (walls), noise }\end{array}$} \\
\hline & $72 \times$ Bnormal & \\
\hline & $6 \times$ Btoroidal & \\
\hline \multirow{2}{*}{$\begin{array}{l}\text { in-vessel flux loops for } \\
\text { equilibrium reconstruction and } \\
\text { real-time control }\end{array}$} & 4 full loops in 9 sectors & $\begin{array}{l}\text { current standard method } \\
\text { long-term failure, drifts, } \\
\text { manufacturing, noise }\end{array}$ \\
\hline & 120 saddle loops & $\begin{array}{l}\text { current standard method } \\
\text { long-term failure, drift, 3D } \\
\text { effects (ferritic inserts, TBM), } \\
\text { image currents (walls), noise }\end{array}$ \\
\hline \multirow{3}{*}{$\begin{array}{l}\text { in-vessel probes in the divertor } \\
\text { region for reconstruction of the } \\
\text { strike points and separatrix } \\
\text { position }\end{array}$} & $36 \times$ Btangential & \multirow{3}{*}{$\begin{array}{l}\text { current standard method } \\
\text { long-term failure, drift, 3D } \\
\text { effects (divertor structures and } \\
\text { coils), noise }\end{array}$} \\
\hline & $36 \times$ Bnormal & \\
\hline & $1 \times$ Btoroidal & \\
\hline \multirow{2}{*}{$\begin{array}{l}\text { in-vessel sensors for high- } \\
\text { frequency / high mode number } \\
\text { MHD instabilities }\end{array}$} & $>300 \times \mathrm{Br}$ & \multirow{3}{*}{$\begin{array}{l}\text { current standard method } \\
\text { long-term failure, frequency } \\
\text { calibration, manufacturing, } \\
\text { layout optimization, drifts, } \\
\text { noise, 3D effects (passive } \\
\text { structures, image currents) }\end{array}$} \\
\hline & $>100 \times$ Bnormal & \\
\hline $\begin{array}{l}\text { in-vessel flux loops for low- } \\
\text { frequency / low mode number } \\
\text { MHD instabilities }\end{array}$ & 72 saddle loops & \\
\hline $\begin{array}{l}\text { measurements of diamagnetic } \\
\text { flux for stored energy }\end{array}$ & $\begin{array}{l}\text { 2-turns diamagnetic flux loop } \\
\text { in } 3 \text { separate machine sectors } \\
24 \text { saddle loops }\end{array}$ & $\begin{array}{l}\text { current standard method } \\
\text { calibration, compensation for } \\
\text { passive structures, drift, failure, } \\
\text { 3D effects (ferritic inserts, } \\
\text { TBM), image currents (walls), } \\
\text { noise, ELMs (time resolution) }\end{array}$ \\
\hline \multirow{2}{*}{$\begin{array}{l}\text { Rogowski coils for halo current } \\
\text { measurements }\end{array}$} & 360 for blanket modules & \multirow{2}{*}{$\begin{array}{l}\text { current standard method } \\
\text { long-term failure, 3D effects } \\
\text { (ferritic inserts, TBM), image } \\
\text { currents (walls), noise }\end{array}$} \\
\hline & 60 in divertor & \\
\hline \multirow[b]{2}{*}{$\begin{array}{l}\text { ex-vessel inductive probes for } \\
\text { equilibrium reconstruction (and } \\
\text { real-time control?) }\end{array}$} & $180 \times \mathrm{Bta}$ & \multirow{2}{*}{$\begin{array}{l}\text { current standard method } \\
\text { long-term failure, drifts, 3D } \\
\text { effects (ferritic inserts, TBM), } \\
\text { image currents, noise }\end{array}$} \\
\hline & $180 \times$ Bnormal & \\
\hline \multirow{2}{*}{$\begin{array}{l}\text { ex-vessel steady-state sensors } \\
\text { for equilibrium reconstruction } \\
\text { (and real-time control?) }\end{array}$} & $60 \times$ Btangential & \multirow{2}{*}{$\begin{array}{l}\text { new technology } \\
\text { long-term failure, 3D effects } \\
\text { (ferritic inserts, TBM), image } \\
\text { currents, noise }\end{array}$} \\
\hline & $60 \times$ Bnormal & \\
\hline $\begin{array}{l}\text { ex-vessel flux loops for } \\
\text { equilibrium reconstruction }\end{array}$ & 5 full loops & $\begin{array}{l}\text { 3D effects (ferritic inserts, } \\
\text { TBM), image currents, noise }\end{array}$ \\
\hline $\begin{array}{l}\text { Rogowski coils inside TF coil } \\
\text { casing to measure plasma } \\
\text { current }\end{array}$ & $\begin{array}{l}9 \text { TF coils fitted with these } \\
\text { Rogowski sensors }\end{array}$ & $\begin{array}{l}\text { current method, new location } \\
\text { long-term failure, drifts, direct } \\
\text { pick-up from TF }\end{array}$ \\
\hline $\begin{array}{l}\text { ex-vessel sensors using } \\
\text { Faraday rotation method to } \\
\text { measure plasma current }\end{array}$ & 4 sensors in 3 machine sectors & $\begin{array}{l}\text { new method, new location } \\
\text { long-term failure, noise }\end{array}$ \\
\hline
\end{tabular}

\section{A. Measure Magnetic Flux and Field Around the Plasma to Reconstruct the Magnetic Equilibrium}

As in all current tokamaks, values of local magnetic fields and fluxes will be mainly derived in ITER from inductive sensors, measuring $d \Phi_{\mathrm{B}} / d t$, where $\Phi_{\mathrm{B}}$ is the total magnetic flux enclosed by a wire loop. Although the time derivative $(d / d t)$ can in itself yield useful information on the currents flowing in the passive structures which surround the measurement device, the signals have to be integrated to be used for equilibrium reconstruction (in real time for protection and control, postpulse for more physics-oriented data analysis). These flux and field measurements are made inside and outside the vacuum vessel. Fig. 1 shows some examples of these sensors, as currently being prototyped. As ITER has two 60 -mm-thick diffusive walls, the measurements made outside the vessel need careful analysis and modeling of the currents flowing in the walls, as the resulting phase delay creates difficulties in stabilizing the naturally unstable $n=0$ vertical and $n=1$ tilt modes. Similarly, the detailed magnetic field structure in the divertor region, which is affected by the presence of the divertor coils, must be known accurately to determine precisely the location of the separatrix and the strike points. To this end, specific inductive magnetic sensors are foreseen for installation around the divertor region. These sensors, whose assembly layout is shown in Fig. 2, are subject to strong radiation fluxes, thermal gradients, and electric field changes, particularly during a disruption, and would require active cooling to keep the temperature excursion within the nominal $\Delta T=10{ }^{\circ} \mathrm{C}$ range, which in turn imposes 


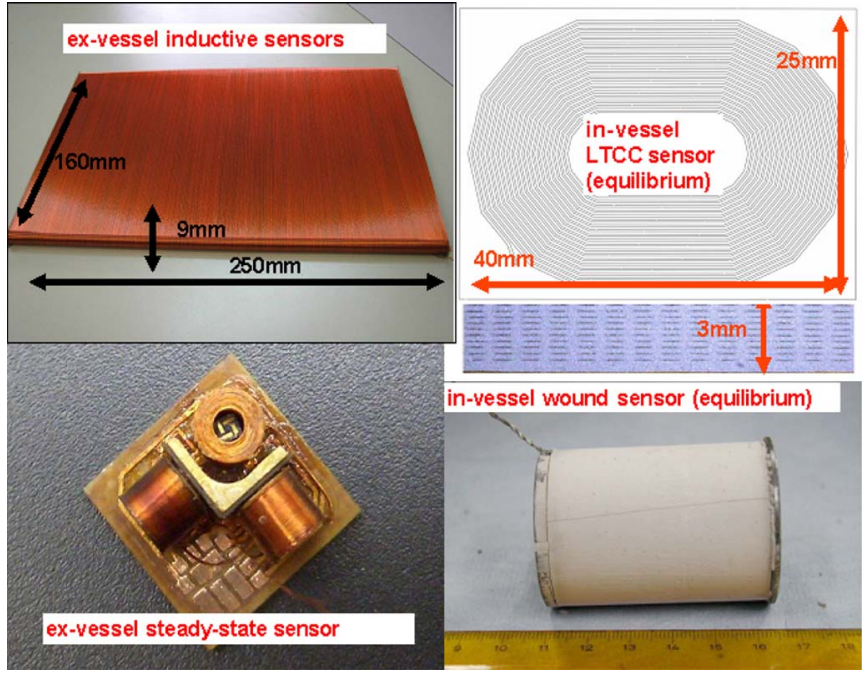

Fig. 1. Four examples of magnetic sensors being currently prototyped for measurements of magnetic fluxes and fields to be used for equilibrium reconstruction.

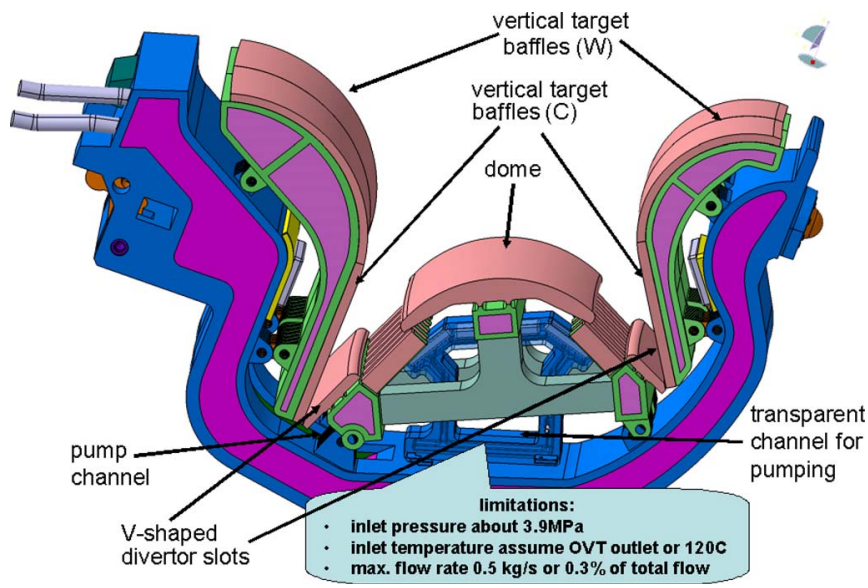

Fig. 2. Layout of the divertor cassette. The magnetic sensors are currently intended to be located behind the inner and outer vertical targets, under the dome, and under the inner and outer neutral particle reflector (plates that together with the lower ends of the vertical target form a "V" shape).

very severe constraints on their design and assembly within the divertor cassette [5]. Together with measuring the magnetic fields and fluxes in the poloidal plane, the variation in the toroidal flux also provides a direct estimate of the toroidal field and information on the plasma stored energy. To this end, the diamagnetic flux loop is currently intended to have a sampling rate of at least $10 \mathrm{kHz}$ in order to cope with the fast variations caused by edge-localized modes, and it is designed with a twoturn layout (for in situ compensation of geometrical effects) located in three different machine sectors (for redundancy and assessment and direct compensation of 3-D effects due to the vessel walls). This design is however difficult to implement due to lack of space. In addition to the conventional Mirnov-type and flux-loop sensors, for which a schematic system layout is shown in Fig. 3, other techniques are also being considered for application to the ITER long-pulse operation. As two specific examples, R\&D studies are being performed on exvessel 2-D Hall probes and neural networks [6]. Inductive sensors made with wound wire or a sintered stack of ceramic layers with

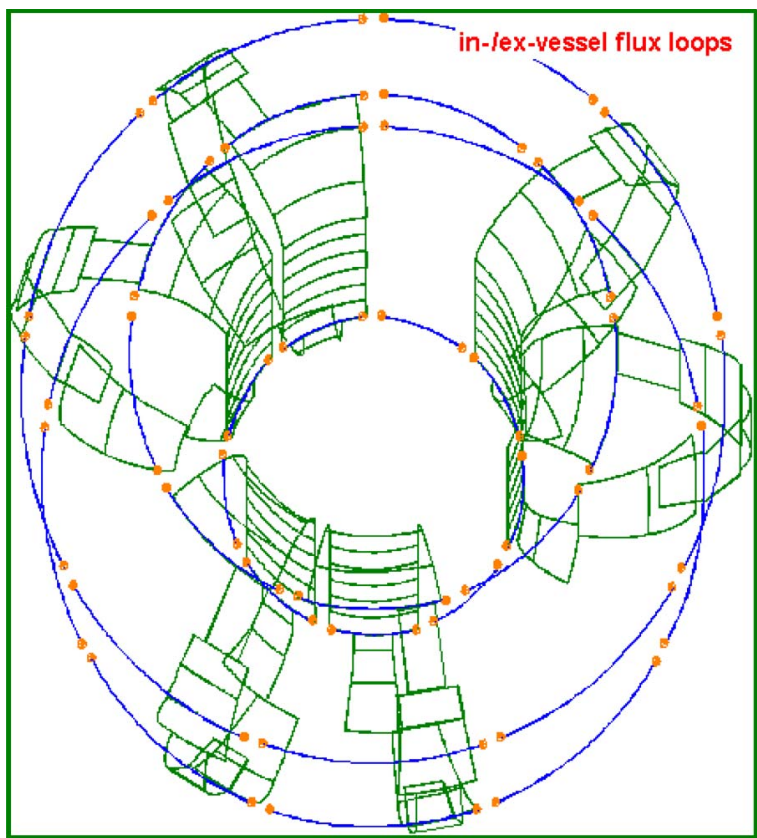

Fig. 3. Schematic layout of the flux loops as currently foreseen for installation on ITER.

printed metallic lines [Low Temperature Cofired Ceramic (LTCC)] are also being investigated for invessel installation [7]. These applications correspond to the axis-symmetric (2-D) model of the tokamak plasma, but the same magnetic diagnostic set has to provide the non-axis-symmetric (3-D) field distribution. This is intended to be used as a correction for the error field resulting from constructional imprecision and from the presence of non-axis-symmetric magnetic structures, such as the ferritic inserts used to reduce the toroidal field ripple and the test blanket modules (TBMs).

\section{B. Measure the Total Plasma Current}

These data have been historically provided by a Rogowski coil measuring the contour integral of the magnetic field, yielding the current passing through the enclosed surface. When placed around the vacuum vessel, this loop signal includes the contribution of the currents flowing in the wall, and the measurement is affected by precise knowledge of these currents. Whereas older tokamaks installed specific Rogowski coils to measure such a loop-integrated current, poloidal field measurements are now currently used to create a "virtual" Rogowski coil by a weighted sum of the individual signals, which is also the present ITER plan. The magnetic system on the TCV tokamak is a standard example of this approach [8], [9]. Nonetheless, conventional Rogowski coils are being developed to sit inside the TF coil casings at liquid helium temperature, and a schematic of this system is shown in Fig. 4(a). Furthermore, a fiber-optic Faraday rotation measurement device [10] is under development, resulting from a collaboration between SCKCEN and CEA-Cadarache, with an overview of its layout shown in Fig. 4(b): the main advantage of this system is that it does not require integration. The first measurements have been recently carried out on Tore Supra and are very promising. 


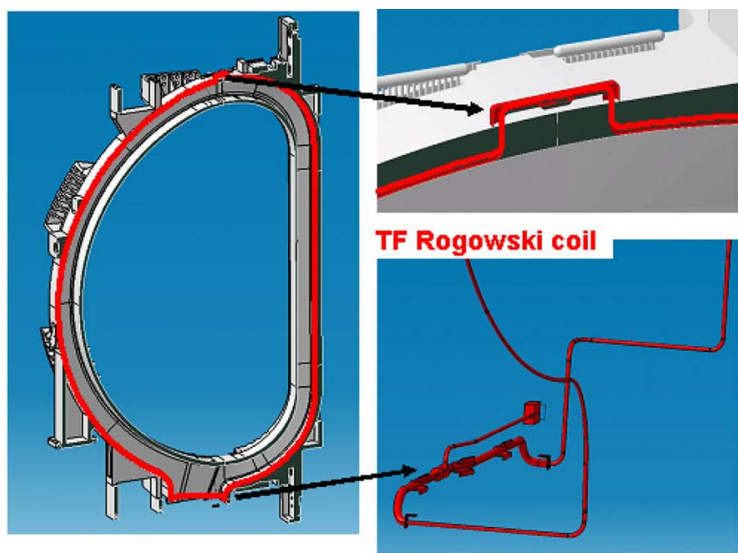

(a)

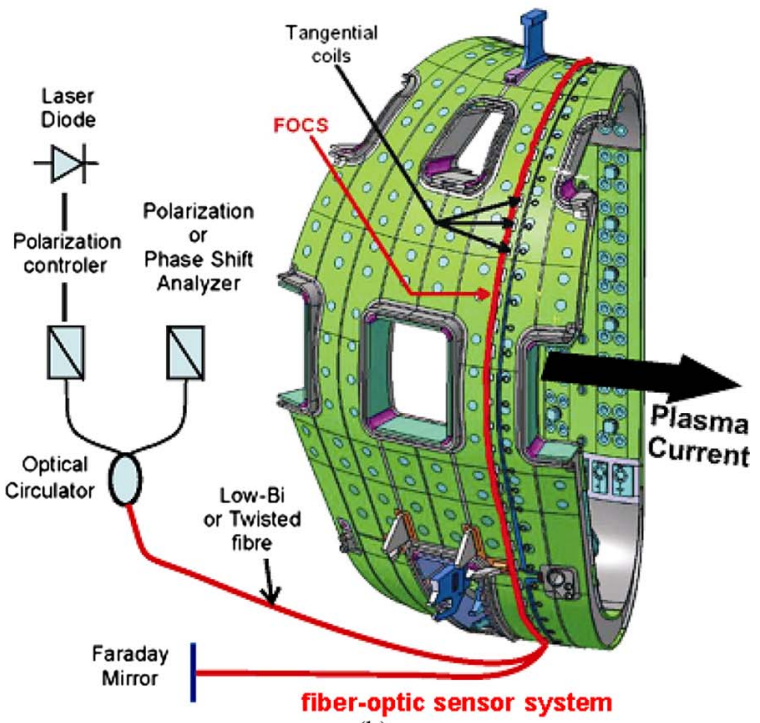

(b)

Fig. 4. (a) Schematic overview of the Rogowski coils to sit inside the toroidal field casing, to be used for the measurement of the plasma current. (b) Schematic overview of a fiber-optic Faraday rotation measurement device, to be used for the measurement of the plasma current.

\section{Measure the Currents Flowing Between the Plasma and the Vacuum Vessel Walls (Halo Currents)}

The main interest of the halo current measurement studies resides in machine protection. Halos are generally non-axissymmetric and localized phenomena, as they depend on the specific metallic structures attached to the vessel wall, and can generate significant and fast varying forces when crossed with the tokamak's equilibrium magnetic fields. Hence, a large number of sensors need to be deployed, using different technologies, such as conventional Rogowski coils and current shunts, so as to maximize the quality of the data being gathered. Moreover, it can be shown [11] that a plasma deformation with eigenmode numbers $(m, n)$ produces halo currents whose fundamental components are $(2 m, 2 n)$ (and many higher harmonics). Therefore, according to sampling theory, at least $(4 m+1,4 n+1)$ sensors are required in order to "recognize" the fundamental component of the halo current distribution. Therefore, the currently proposed number and layout of sensors in ITER gives correct information on plasma deformations with periodicity not higher than $(m / n=2 / 2)$ and partial information up to

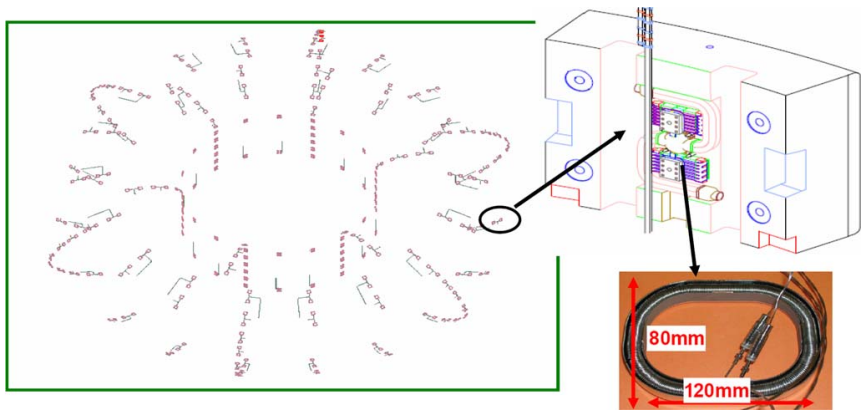

Fig. 5. Schematic overview of the proposed implementation for the Rogowski coils to be used for halo current measurements around the blanket modules.

$(m / n=4 / 4)$. Conventional Rogowski coils to fit around the blanket modules are being designed on the basis of the sensors which are currently operational on JET [12], and an overview of the layout of this system is shown in Fig. 5. In addition to Rogowski coils, which are usable only during transient (disruptive) events, current shunts are under consideration for the measurement of steady-state currents from the plasma into the divertor plates. The use of shunts to estimate the current flowing in the purely poloidal divertor cassettes is under consideration due to demonstrated usefulness of an estimate of the localized current deposition at the wall on ASDEX Upgrade [13]. The main issues for installation on ITER of halo current measurement devices are, first, the feasibility of such system, as the number of sensors for the blanket modules implies a very large amount of additional wiring (as $>360$ Rogowski only equip about $1 / 3$ of all blanket modules) and, second, specifically for the divertor shunts, whether the additional constraints that can be put on the equilibrium reconstruction provided by a single-lumped poloidal current measurement in the divertor cassette justifies such a complex addition to this already very challenging system.

\section{Measure the Fast Fluctuations in the Equilibrium Magnetic Field Driven by MHD Instabilities}

MHD activity drives magnetic field fluctuations at frequencies much higher than the plasma skin depth. Since these instabilities are non axis symmetric, many sensors need to be used to reconstruct the spatial and temporal variations of these HF signals in ITER, to provide essential data on the MHD eigenmode structure with toroidal and poloidal mode numbers $|n| \leq 30$ and $|m| \leq 60$, respectively, and to frequencies at least on the order of $300 \mathrm{kHz}$. In addition to the standard wound inductive sensors of conventional Mirnov-type design, two other technologies are being considered and are currently being prototyped to perform these HF magnetic measurements [14]-[16]: laser-cut nonconventional Mirnov-type pick-up coils and LTCC sensors. Fig. 6 shows some of these as-built prototypes. The most promising design is the LTCC sensor, as this allows for a significant reduction in the space occupied by the measurement device and removes all difficulties related to the manufacturing of a complex ceramic body and the assembly of a winding pack onto it. The main difficulty with the LTCC technology is related to the metallic ink used to print the circuit onto the 


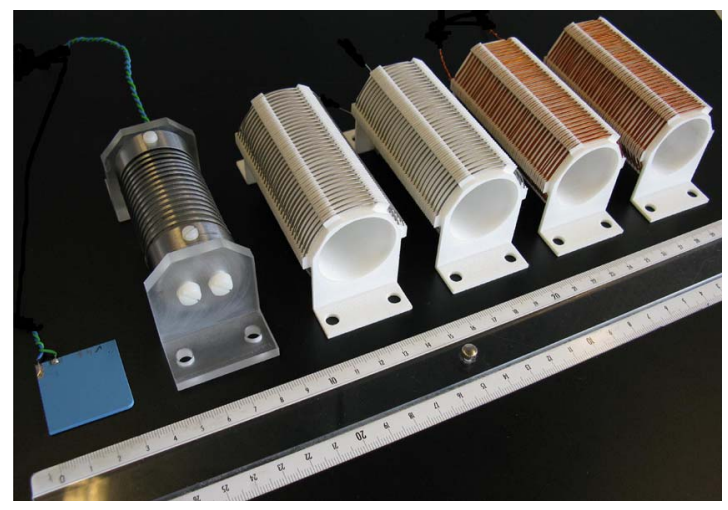

Fig. 6. Some examples of the HF sensors being prototyped for ITER. (From left to right) One LTCC sensor, one laser-cut nonconventional sensor, and four conventional Mirnov-type coils wound in tungsten and copper (two off, each with different grooving for the ceramic spacers).

green sheets, as current processes mainly use silver and gold, whereas such materials may need to be avoided in ITER due to a perceived risk of transmutation to cadmium and mercury under the expected neutron and radiation fluxes. It is however intuitively expected that, as an alloy is formed when sintering an LTCC sensor, the metallic ink will be sealed in the surrounding ceramic green tape, so that $\mathrm{Cd}$ and $\mathrm{Hg}$ outgassing from the LTCC structures would be essentially zero, as any of such atoms should attach to and therefore remain confined within the structural imperfections of the metallic tracks. Similarly, the coil-wiring connections can be sealed by applying a vacuum ceramic paste or glass encapsulation after bonding. A dedicated materials and radiation testing program is currently foreseen to confirm these assumptions.

The number and the spatial distribution of these sensors will also need to be carefully optimized to satisfy the very stringent ITER measurement requirements [14], [17], [18]. Specifically, the currently foreseen layout with $\sim 170$ sensors in total does not allow sufficient accuracy in the measurement of instabilities with mode numbers $|n|>15$ and $|m|>20$ nor distinction between ballooning and antiballooning instabilities. An optimized sensor layout with $\sim 350-400$ sensors is being proposed to satisfy the current ITER measurement requirements and allow distinction between ballooning and antiballooning modes at the expense, however, of a much larger number of invessel services and data-acquisition modules and bandwidth that would need to be procured and installed. Two further difficulties for the HF magnetic diagnostic system arise from the fact that such sensors are currently intended to be either "buried" within ad hoc cutouts in the blanket modules or in the small gap (of thickness $<20 \mathrm{~mm}$ ) between the blanket and the first vessel wall. This not only adds a constraint on the volume available for installation, hence most definitively favoring the LTCC design, but also raises some doubts on the achievable frequency response of these sensors, as the currently unknown electrical properties of the blanket modules may also impact the measurement performance of this diagnostic. Therefore, it is intended to finalize a proposal for the system layout for the HF magnetic diagnostic system and to continue with detailed prototyping activities, only after the design of the vessel and blanket modules will be completed and their electrical properties can be assessed fully.

\section{E. Reconstruct the Plasma Equilibrium}

The ensemble of magnetic measurements recorded at low frequencies $(<1 \mathrm{kHz})$ in their derivative and integrated forms, combined with measurements of all the active currents driven by external power supplies, is used to perform a reconstruction of the axis-symmetric equivalent magnetic equilibrium, namely, a solution of the tokamak equilibrium equation which would produce a set of signals as close as possible to the measured signals while respecting a regularized solution. This reconstruction will need to be provided both in real time for engineering protection and control of the plasma discharge and postpulse for more detailed physics-oriented scientific analysis. Given the many specific difficulties associated with the ITER environment, for instance the effect of 3-D passive structures and long-pulse drifts in the electronics, it is planned to perform an optimization between all currently used approaches to this challenge, so as to minimize the risks in such analysis through a diversity of methodologies.

\section{F. Provide Appropriate Feedback-Control Error Signals}

The plasma equilibrium has two main instabilities that can be stabilized by magnetic feedback control: the $n=0$ vertical positional instability, which can be attributed to the elongation of the equilibrium by an imposed quadruple field and the dissipation of induced $n=0$ image currents in the vacuum vessel and other passive structures, and the $n=1$ tilting instability, which can similarly be attributed to the dissipation of $n=1$ image currents in the vacuum vessel. Correcting these instabilities requires prompt action by power supplies: the error signal driving the feedback loop is derived from real-time data produced by the magnetic diagnostic set. Time delays or phase changes in the signals can cause prejudice to the quality of the feedback control. These are likely to occur in ITER due to the large number of complex internal conducting structures, and specific algorithms need to be devised to compensate for such distortions. The remaining part of equilibrium control, which is essentially used to tune the plasma shape, is less demanding in terms of allowable delay but is more demanding in the precision of the integrated signals to meet the error requirements on the reconstruction of the equilibrium. Integration into the real-time CODAC Synchronous Databus Network allows the signals, feedback controllers, and power supplies to communicate efficiently between themselves for plasma protection and control.

\section{G. Provide Signals for Protection of Investment and Safety}

The development of the ITER safety case is underway, and the need to provide a SIC class measurement of the plasma current is being discussed. This would be the only SIC requirement for the magnetic diagnostic set. Since the magnetic diagnostic is responsible for controlling the high free (internal) magnetic energy of the plasma current itself and the (externally) controlled magnetic energy of the active coil currents, loss of control has serious consequences, such as loss of availability during recovery after a disruption, and a reduction in the total number of disruptions that can be allowed before refurbishment 
of plasma-facing components becomes needed. Hence, it is clear that a significant fraction of the ITER magnetic diagnostic output will be connected to the plasma-control system, with some data also connected to the central interlock system. These decisions clearly impact on the project costs and on the definition of the acceptable risks in terms of the measurement performance and on the required availability and reliability over the lifetime of ITER.

\section{Novel AND SPecific ITER Challenges}

A number of challenges for implementation of the magnetic diagnostic set in ITER are novel to the tokamak community, as they depend on the harsh environmental conditions of ITER, specifically the long pulse length; the expected neutron, $\gamma$, and radiation fluxes, fluency, and doses; and the need for access-free diagnostic maintenance over the machine lifetime. These have been the subject of continuing R\&D activities and are briefly overviewed in the following sections.

\section{A. Long Pulse Length}

This challenge to current standard electronic integrators has been adequately addressed over the last few years [19]-[22]. Much attention is required, particularly because spurious electromotive forces (EMFs) due to radiation or thermal effects, as described in more detail below, can make this a very critical issue unless a suitable and very reliable mitigation of these unwanted EMFs can be fully implemented and guaranteed.

\section{B. Radiation and Neutron Resistances}

Long-term resistance and lifetime reliability of the various sensor components to neutrons and radiation are being met by appropriate selection of materials. Numerical simulations of such effects are difficult, as it is already clear from preliminary tests that much of the possible damage to the sensors will be caused by their specific and individual structural properties and particularly by the presence of defects. Hence, these analyses will have to be confirmed by future radiation testing on dedicated facilities on prototypes as close as possible to the as-built sensors and using neutron, $\gamma$, and radiation spectra as similar as possible to those expected in ITER.

\section{Availability and Precision}

The operation of ITER will require a system availability and precision in the output data above those required in current experiments, so as to meet the intended goals within the project lifetime. In particular, the plasma separatrix must be controlled to within a very high precision, relative to the size of the device, on the order of no more than a few millimeters as compared to a minor radius $\sim 2 \mathrm{~m}$ and during very rapid and time-varying intrinsic perturbations to the plasma equilibrium, such as those caused by edge-localized modes. This will require specific $\mathrm{R} \& \mathrm{D}$ work to meet the long-term operational requirements, flexible and accurate tools for equilibrium reconstruction, and ingenious feedback controllers to tackle the intrinsic perturbations to the plasma equilibrium.

\section{Radiation- and Neutron-Induced EMFs}

Invessel cables and sensors bombarded by neutron and $\gamma$ fluxes generate a noninductive EMF due to energetic electrons produced within the cables and the surrounding structures. This effect appears as an EMF at the integrator input of all invessel sensors and leads to a cumulative error in the integrator output baseline [23], [24]. Whereas the neutron-induced effects are well understood, the often dominant effects caused by $\gamma$ are not believed to be sufficiently reproducible to be compensated on the basis of modeling of the measured rates. The only mitigation other than choice of wire materials is to generate large-enough signals in the sensors and reduce them at the front-end electronics. As the level of the radiation-induced EMF signals cannot be estimated precisely, given the foreseeable uncertainties in the neutron and radiation fluxes and the manufacturing tolerances on the invessel wires, exvessel and steady-state sensors have also been included in the baseline system design to provide further mitigation strategies for this source of errors.

\section{E. Thermally Induced EMF}

Cables subject to temperature gradients along their length produce a nonzero thermoelectric EMF due to manufacturing imperfections [25], [26]. In addition to this, nucleartransmutation products can lead to a significant thermally induced EMF at the integrator input during the pulses for invessel sensors, causing again a cumulative error in the integrator output baseline [27]. As compensation is currently not foreseen, mitigation of this source of error is only based on thermal-gradient reduction in the sensors and cables and on high signal amplitudes and material choice. Specifically, the option of glass-fiber-insulated twisted pair cables instead of mineral-insulated cables is being considered. The importance of this effect on LTCC sensors is also currently being investigated.

\section{F. Mechanical Distortion During Pulses}

Distortion of the invessel mechanical support structure for the sensors can occur between different in situ measurements (for instance, via photogrammetry surveys) or even during a plasma pulse. These movements can lead to erroneous interpretation of the magnetic signals. The large forces and the thermal cycling are capable of presenting a challenge of mechanical stability on the position and particularly on the viewing angle of the sensors with respect to the magnetic field axis, which may, in turn, lead to an erroneous separation between the 3-D components of the measured fields and fluxes.

\section{Present Magnetic Diagnostic Set for ITER}

As summarized in Table I, $>1700$ sensors are foreseen for the magnetic diagnostic set in ITER, compared to $\sim 500$ for JET and $\sim 300$ for TCV, to name just a couple of currently operating tokamak devices. This large (but actually not that large when comparing the size of these machines) number of sensors for the ITER magnetic diagnostic system is driven by several considerations, which are separately highlighted as follows.

First, non-axis-symmetric $n=1$ and $n=2$ modes need to be filtered out for real-time control and postpulse equilibrium 
reconstruction by averaging multiple toroidal arrays, leading to an increase in the number of sensors by typically a factor of $\sim 2-3$. For the same purpose, a large number of poloidal locations are equipped, providing considerable redundancy to combat the risk of statistical failure of individual sensors. Moreover, for non-axis-symmetric mode reconstruction, the resolution of the poloidal and toroidal mode numbers is higher than usual and requires a larger number of probes.

Second, multiple unevenly spaced arrays of HF sensors are needed to unambiguously resolve the predicted spectrum of MHD fluctuations in order to satisfy the ITER measurement requirements. Furthermore, as the operational experience on current tokamaks indicates that such HF sensors are often more prone than the others to statistical failures, it is foreseen to develop and possibly deploy multiple technologies to perform such measurements so as to reduce the common-mode failure risks via a diversity of methodologies.

Third, diagnosing the halo currents in the blanket modules requires $\sim 1 / 5$ of the magnetic sensors but only equips $\sim 1 / 3$ of all blanket connections. As halo current measurements are essential for machine protection, the choice of equipping just a subset of invessel location is questionable by definition, as one would want to monitor halo currents all over the vessel, and particularly around the most important or "delicate" structures. This, however, implies a very large number of wiring, connectors, and invessel services, so that an optimum compromise will have to be made.

Fourth, steady-state sensors need to be installed exvessel, where the neutron and radiation fluxes are very much attenuated, to mitigate the risks related to radiation- and thermally induced EMFs, therefore duplicating in many aspects the invessel measurements. This duplication provides some diversity, although the frequency response of the invessel and exvessel sensors is clearly different due to the double 60 -mm-thick vessel wall, and will require considerable $R \& D$ before installation and detailed commissioning and troubleshooting during the initial phase of operation to guarantee their use as a long-term fallback option. To this end, noninductive sensors and steady state will also need to be deployed exvessel so as to mitigate the risks associated to incorrect understanding of the effect of the walls. These sensors, and particularly radiation-resistant Hall probes, represent also a good candidate toward reducing the risks associated to excessive EMF drifts induced by radiation and temperature gradients.

Fifth, external Rogowski coils and Faraday rotation current measurements provide a backup and possibly a SIC class measurement for the plasma current in addition to the currently foreseen use of a "virtual" Rogowski, which is in itself sensitive to 3-D effects such as those associated to the ferritic inserts. However, use of these measurements does not constitute functional diversity, since these coils do not generate the information required to control the equilibrium or provide stability.

Finally, to satisfy the ITER measurement requirements over the machine lifetime, an even larger than usual number of sensors need to be installed to provide considerable redundancy and mitigate the risk of statistical failure of individual sensors. It is foreseen that some essential measurements will be performed using different technologies, so as to reduce the risk of common-mode sensor failure and provide backup via diversity of instrumentation.

\section{Risk AnAlysis and Mitigation Through R\&D ACTIVITIES AND PLANNING}

Most magnetic diagnostic systems appear on most tokamaks but never with the risks associated with ITER operation. As ITER will simply not be able to operate without a functional magnetic diagnostic system, it becomes paramount to review and address the possible risks in achieving such a goal [28]. Direct risks to the mechanical integrity of the ITER device generated by the magnetic diagnostic systems themselves are negligible, since there are no vacuum interfaces (other than outgassing), and there is no physical danger to ITER from the functionality provided by the sensors. The absence of vacuum interfaces stems from a project decision to separate the sensors from the invessel service wiring, allowing the service wiring to be developed independently for thermocouples and bolometers. All risks to the project therefore stem from unavailability or unreliability of the required functionality, which may lead to inadequately precise control of the plasma equilibrium or to the initiation of disruptive events, both of which represent a significant risk to the ITER device. These "residual" risks can be classified in three groups, related to different time points throughout the entire machine lifetime:

1) (not) delivering the measurement requirements for initial plasma operation;

2) (not) delivering the measurement requirements for first full-performance (ignited) plasmas;

3) (not) delivering the measurement requirements for the last plasma, i.e., at the end of the machine lifetime.

A detailed planning analysis has been performed to assess mitigation strategies for these risks, and this has been included in the Project Plan for the development of the ITER magnetic diagnostic, referred to as the MAGDIAG project. The overall Project Plan has been subdivided into individual workbreakdown-structure (WBS) tasks to facilitate the interlinking between different activities.

The internal scientific consistency of the full magnetic diagnostic set is still based on the one which has been outlined in the ITER 2001 Design Description Document, which was later updated in 2004. However, the overall ITER machine design has drifted from a proposed set dating from 1998, with continual revisions of the machine itself and of its goals. Therefore, and as of today, the major outstanding uncertainties in the successful completion of the MAGDIAG project such that it would be meeting all the ITER measurement requirements are considered to be as follows:

1) the technical and scientific risks associated in using the magnetic data to meet the very stringent ITER measurement requirements, particularly when considering the novel 3-D passive structure effects and the 2-D and 3-D ferromagnetic effects;

2) the unceasing changes to the ITER project itself, excluding convergence of the work being performed at the level of engineering design, or even conceptual design for some elements. 


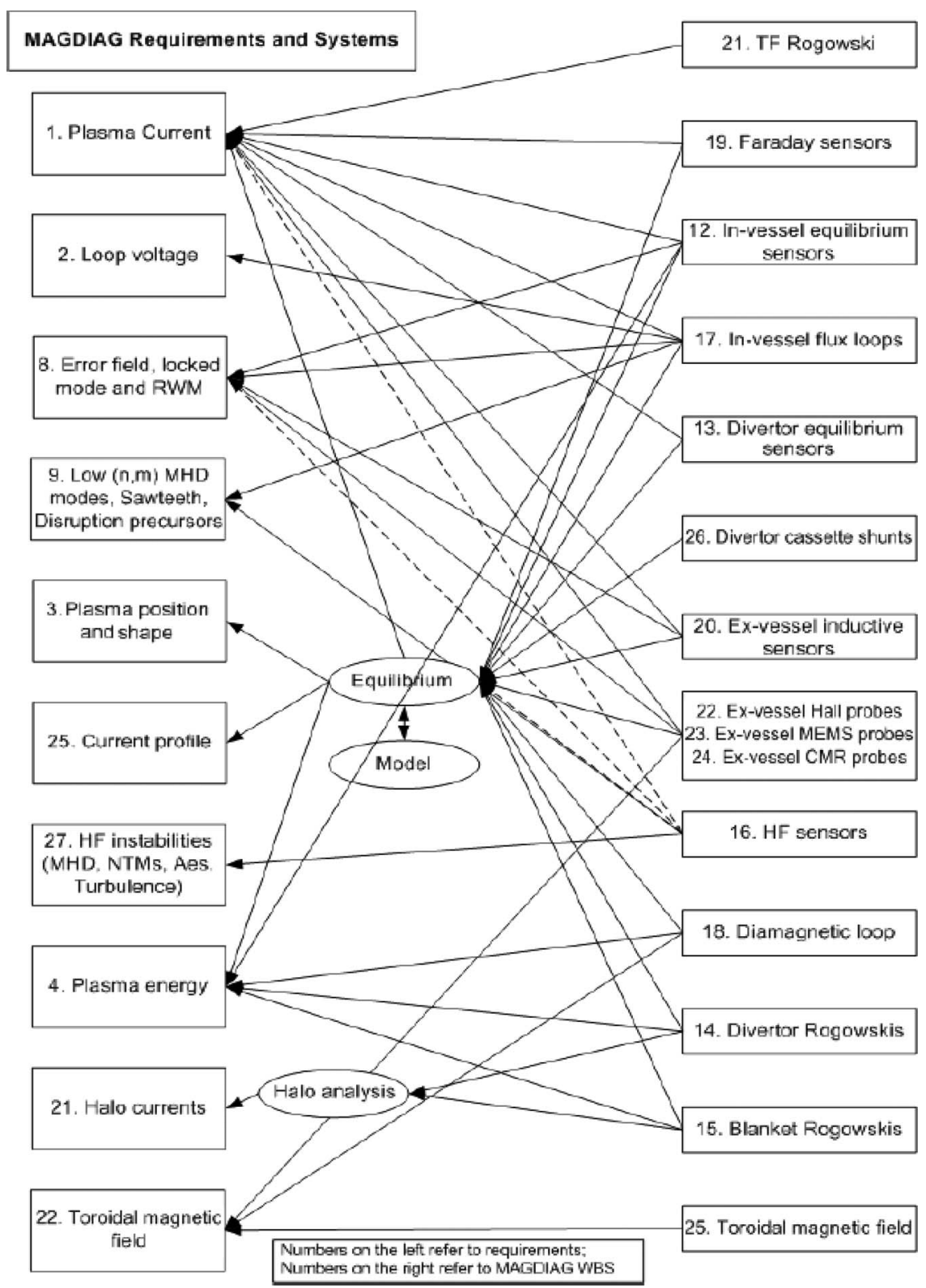

Fig. 7. Link between meeting in full the ITER measurement requirements for the magnetic diagnostic system and selecting the subsystems handled under WBS12-26. Ellipses are intermediate treatment of the data generated by sensors on the route in meeting requirements.

These uncertainties are reflected in the Project Plan, and the second point also impacts very strongly on the Project Schedule. Each magnetic diagnostic set needs stable measurement requirements and stable engineering drawings, which are not yet fully available for ITER at this time.

The formal ITER measurement requirements for the full magnetic diagnostic set are presented in [3] and [4]. Fig. 7 shows the link between meeting these requirements and selecting the subsystems handled under the different WBS tasks in the MAGDIAG project. Fig. 7 immediately shows the interconnected nature of the magnetic diagnostic systems. The figure already shows the following points.

1) There are few requirements which are met by one singlecomponent system, i.e., the loop voltage.

2) There is no single-component system which satisfies one single requirement.
3) There are intermediate usages which require system information outside the MAGDIAG scope, i.e., PF coil currents.

4) There are multiple WBS packages which satisfy a single purpose, although being used to meet multiple requirements.

5) There is no explicit requirement to reconstruct the equilibrium (as only the separatrix gaps are explicitly required).

6) There is no explicit requirement to provide control signals (but implicit in the measurement of the vertical position).

7) There is no explicit requirement to provide signals to calibrate an electromagnetic model (which therefore might be performed with reduced reliability requirements and hence reduced cost).

8) There is no plan for measuring the induced and magnetization currents. 
TABLE II

BREAKDOWN OF ASSUMED RESOURCES FOR THE ITER HF MAGNETIC SYSTEM (WBS16)

\begin{tabular}{|l|l|l|}
\hline WBS element & cost $(\mathbf{k} €)$ & effort (man-days) \\
\hline WBS16.1 - System Management & 0 & 1 \\
\hline WBS16.2 - Development & 644 & 1381 \\
\hline WBS16.2.1 - Review and Plan & 0 & 175 \\
\hline WBS16.2.2 - System Design & 7 & 452 \\
\hline WBS16.2.3 - Component Design & 0 & 150 \\
\hline WBS16.2.4 - Component Prototyping & 534 & 552 \\
\hline WBS16.2.5 - Component Qualification & 50 & 20 \\
\hline WBS16.2.6 - Design Decisions & 53 & 32 \\
\hline WBS16.3 - Engineering Design & 27 & 676 \\
\hline WBS16.3.1 - Mechanical Design & 12 & 499 \\
\hline WBS16.3.2 - Electrical Design & 15 & 177 \\
\hline WBS16.4 - Production & 787 & 583 \\
\hline WBS16.4.1 - Contracting & 18 & 137 \\
\hline WBS16.4.2 - Pre-series & 128 & 117 \\
\hline WBS16.4.3 - Manufacturing & 510 & 40 \\
\hline WBS16.4.5 - Test and Acceptance & 131 & 289 \\
\hline WBS16.5 - Installation & 103 & 225 \\
\hline WBS16.6 - Commissioning & 93 & 907 \\
\hline
\end{tabular}

As a specific example of a WBS package, we focus on the HF magnetic sensors (WBS16), and the breakdown of the estimated resource (manpower and cost) requirements for this WBS is shown in Table II. The current system design comprises a large number (200-500) of inductive magnetic sensors which have to be sited inside the vacuum vessel with minimum electromagnetic shielding to provide the required frequency response. The layout of the sensors around the torus has to be studied for compatibility with allowed space occupancy, added value for mode identification, and shielding from the harsh environment. The design of the individual sensors themselves has to cope with maintenance-free operation during the lifetime of the ITER project, even though some of the components are intended to be designed with the possibility of remote maintenance. Therefore, the principal challenges to this diagnostic to meet the ITER measurement requirements [3], [4] are as follows:

1) meeting the requirements to identify the small lowwavelength perturbations;

2) guaranteeing appropriate sensitivity in the presence of massive passive structures;

3) guaranteeing the frequency response of the sensors and, at the same time, meeting the sensitivity requirement;

4) meeting the environmental conditions of radiation, thermal, and mechanical stresses;

5) meeting the high level of reliability compatible with the low-maintenance requirement.

As reported in [14]-[18], technical solutions for the design and construction of the sensors themselves have been explored, and adequate solutions are considered to exist, although there is no design fully accepted as of today. Two radically different approaches to the design of the sensors are being examined, namely, conventional and nonconventional wired pick-up coils of different designs and LTCC sensors with different spiral winding layouts. Both of these approaches require additional $R \& D$ before the final choices could be made. Once a sensor design is approved, the appropriate sensor-mounting interfaces will have to be developed. Potential designs will also have to be subject to qualification for outgassing and for thermal, mechanical, thermoelectric, and radiation effects. The main remaining issues that need to be addressed within the Project Planning are therefore related to the following conditions.

1) The ITER target specifications on mode number identification are considered to be unreachable with the currently planned number of $\sim 170$ sensors.

2) The number and position of the sensors cannot therefore be considered as converged.

3) The mechanical environments of the vessel and blanket modules have not stabilized adequately to advance the individual sensor design and the system layout beyond the design principles.

The principal risks identified for the successful execution of this WBS16 are shown in Table III. These risks have been taken into consideration in developing the Project Plan, but a full analysis has only a very limited scope as these risks are also affected by other developments. Considering now the implementation of future $R \& D$ activities for this diagnostic set, it is clear that a diversity of solutions appears to be the most appropriate risk mitigation against unknown risks associated with this one-of-a-kind problem. As of today, and considering the tight ITER scheduling, this involves the following processes:

1) developing and assessing in parallel different sensor design using different technologies, so that, hopefully, at least two different technologies can be found to be suitable for installation in ITER - this will reduce the risks associated to "common-mode failure" of one type of sensor because of environmental constraints, such as neutron and/or radiation fluxes;

2) developing and assessing optimized strategies for redundancy in the number of sensors so as to reduce the overall procurement and installation costs-this will reduce the risk associated to the "statistical failure" of individual sensors without compromising the budget requirements;

3) developing and assessing in parallel different overall system layout (i.e., the invessel position of the sensors) in order to meet the intended measurement requirements, so as to be able to cope with possible different constraints and technical specifications that are currently foreseen to be specified at a later date-this will reduce the risk 
TABLE III

PRINCIPAL IDENTIFIED RISKS FOR THE ITER HF MAGNETIC SYSTEM (WBS16)

\begin{tabular}{|c|c|c|c|}
\hline ID & Risk & principal consequences & $\begin{array}{c}\text { approach to mitigate or } \\
\text { avoid }\end{array}$ \\
\hline R. 16.0 & unknown & $\begin{array}{l}\text { loss of identification of } \\
\text { mode numbers and/or loss } \\
\text { of frequency response }\end{array}$ & $\begin{array}{l}\text { diversity of design and } \\
\text { production, safety margin on } \\
\text { number of sensors and } \\
\text { thorough peer-review }\end{array}$ \\
\hline R. 16.1 & $\begin{array}{l}\text { poor grounding rules } \\
\text { generating noise on cabling }\end{array}$ & $\begin{array}{l}\text { noise at the low frequency } \\
\text { end of the MHD spectrum }\end{array}$ & $\begin{array}{l}\text { careful review of the signal } \\
\text { and power cabling close to } \\
\text { the tokamak }\end{array}$ \\
\hline R. 16.2 & $\begin{array}{l}\text { pick-up from in-vessel active } \\
\text { currents not adequately } \\
\text { compensated }\end{array}$ & $\begin{array}{l}\text { noise at the low frequency } \\
\text { end of the MHD spectrum; } \\
\text { potential saturation of the } \\
\text { front-end electronics }\end{array}$ & $\begin{array}{l}\text { choice of location and } \\
\text { precision of drawings of the } \\
\text { active coils }\end{array}$ \\
\hline R. 16.3 & $\begin{array}{l}\text { excessive shielding not } \\
\text { understood during design }\end{array}$ & $\begin{array}{l}\text { poor calibration of the } \\
\text { amplitude and phase at the } \\
\text { high frequency end of the } \\
\text { MHD spectrum }\end{array}$ & $\begin{array}{l}\text { ensure that all design } \\
\text { modifications are validated } \\
\text { by MAGDIAG }\end{array}$ \\
\hline R. 16.4 & $\begin{array}{l}\text { inadequate number of } \\
\text { sensors to meet requirements }\end{array}$ & $\begin{array}{l}\text { uncertainty at the high-n } \\
\text { spectrum, confusing } \\
\text { physics interpretation }\end{array}$ & review the existing design \\
\hline R. 16.5 & $\begin{array}{l}\text { quality of welding of } \\
\text { inaccessible components }\end{array}$ & $\begin{array}{l}\text { excessive loss of sensors } \\
\text { and consequent loss of } \\
(\mathrm{m}, \mathrm{n}) \text { identification }\end{array}$ & $\begin{array}{l}\text { mockups, tests and strong } \\
\text { QA during installation }\end{array}$ \\
\hline R. 16.6 & $\begin{array}{l}\text { excessive statistical loss of } \\
\text { sensors }\end{array}$ & loss of $(m, n)$ identification & $\begin{array}{l}\text { qualification, diversity of } \\
\text { production and design }\end{array}$ \\
\hline R. 16.7 & $\begin{array}{l}\text { systematic loss of sensors } \\
\text { within the allowed statistical } \\
\text { levels (due to halo current } \\
\text { effects, disruption forces) }\end{array}$ & loss of $(m, n)$ identification & $\begin{array}{l}\text { identify and reduce common } \\
\text { mode failures }\end{array}$ \\
\hline R. 16.8 & $\begin{array}{l}\text { degradation of performance } \\
\text { following irradiation }\end{array}$ & loss of $(m, n)$ identification & $\begin{array}{l}\text { qualification, diversity of } \\
\text { production and design }\end{array}$ \\
\hline
\end{tabular}

associated to "common-mode failure" of the entire diagnostic system because of unknown physical unknowns, i.e., operational scenarios not currently considered in the ITER measurement requirements but that may become utilized at a later date (an example of this is plasmas limited on the high-field-side wall).

\section{DisCUSSION AND CONCLUSION}

The primary use of the ITER magnetic diagnostic system is to estimate the plasma equilibrium for the purposes of feedback control of the plasma current, its position inside the vacuum vessel, and the shape of its boundary. To this end, the data from the magnetic sensors are combined in a code which adjusts the measurements to a solution of the Grad-Shafranov equation. ITER imposes severe requirements on the precision with which the measurements can reconstruct the equilibrium, which in turn create very demanding requirements on the accuracy of the individual measurements themselves. Control of the plasma equilibrium is well understood in present-day tokamaks, but the ITER device presents a number of challenges to the precision with which the equilibrium can (and must) be reconstructed.

The first challenge is associated with the long pulses (3000 s) and the need to integrate the voltages provided by the sensors, in most cases, these being the time derivative of the required values. Development of high-quality integrators is essential, and ITER proposes the use of additional "steady state sensors" which do not require such integration. Some of the possible technologies are currently being examined for their reliability in the ITER radiation and thermal environment. The second challenge is associated with the presence of ferromagnetic material of two classes. First, a periodic set of structures is embedded within the vacuum vessel walls with the purpose of spatially smoothing out the local variations of the toroidal field. The second class sits outside the cryostat and is used to shield components from the tokamak magnetic fields. The ferromagnetic material has two nonlinear effects, modifying the system to be controlled and modifying the local value of the magnetic field at the sensors. The challenge is to recover an equivalent toroidally symmetric equivalent estimate of the magnetic configuration from the available set of measurements. The third challenge is associated with the dynamical control of the plasma equilibrium. The presence of massive vacuum vessel walls $(2 \times 60 \mathrm{~mm}$ thick $)$, combined with the required fast recovery from disturbances to the plasma equilibrium, requires such a fast actuator response that exvessel (safer and easier to use) coils were considered to be marginal. Coils have then been placed inside the vacuum vessel for prompt action. However, they create a local perturbation to the magnetic measurements which must be removed from the measurements themselves before these are used for control, as being currently explored on the TCV tokamak. The fourth challenge is the radiation environment coupled with the lack of access for maintainability of the sensors. This requires a guarantee of functionality in the presence of radiation and a long-term guarantee of availability of the sensors themselves. Although each of these four issues appears solvable, when put together, they present an interesting challenge to the implementation of the full diagnostic system. 


\section{ACKNOWLEDGMENT}

This paper was partly carried out within the framework of the European Fusion Development Agreement under Tasks TW4TPDS-DIASUP, TW5-TPDS-DIASUP, TW6-TPDS-DIADES, and TW6-TPDS-DIADEV. The views expressed in this paper are the sole responsibility of the authors and do not necessarily reflect the views of Fusion for Energy or the European Commission.

\section{REFERENCES}

[1] E. J. Strait, E. D. Fredrickson, J.-M. Moret, and M. Takechi, "Chapter 2: Magnetic diagnostics," Fus. Sci. Technol., vol. 53, no. 2, pp. 304-334, Feb. 2008.

[2] D. Testa, R. Chavan, J. Guterl, J.B. Lister, J.-M. Moret, A. Perez, F. Sanchez, B. Schaller, G. Tonetti, M. Toussaint, G. Chitarin, R.S. Delogu, A. Gallo, N. Marconato, S. Peruzzo, A. Encheva, G. Vayakis, C. Walker, H. Carfantan, Y. Fournier, T. Maeder, E. Hodgson, J. Romero, R. Vila, A. Le-Luyer, P. Moreau, B. Brichard, and L. Vermeeren, "The magnetic diagnostics set for ITER," in Proc. 23rd SOFE Conf., San Diego, CA, Jun. 1-5, 2009, pp. 1-4.

[3] G. Vayakis and C. Walker, "Magnetic diagnostics for ITER/BPX plasmas (invited)," Rev. Sci. Instrum., vol. 74, p. 2409, 2003, doi:10.1063/ 1.1534388.

[4] ITPA Topical Group on Diagnostics, A. J. H. Donné, A. E. Costley, R. Barnsley, H. Bindslev, R. Boivin, G. Conway, R. Fisher, R. Giannella, H. Hartfuss, M. G. vonHellermann, E. Hodgson, L. C. Ingesson, K. Itami, D. Johnson, Y. Kawano, T. Kondoh, A. Krasilnikov, Y. Kusama, A. Litnovsky, P. Lotte, P. Nielsen, T. Nishitani, F. Orsitto, B.J. Peterson, G. Razdobarin, J. Sanchez, M. Sasao, T. Sugie, G. Vayakis, V. Voitsenya, K. Vukolov, C. Walker, and K. Young, "Chapter 7: Diagnostics," Nucl. Fusion, vol. 47, no. 6, pp. S337-S384, Jun. 2007.

[5] A. Encheva, G. Vayakis, R. Chavan, A. Karpouchov, and J.-M. Moret, "3D thermal and CFD simulations of the divertor magnetic coils for ITER," in Proc. NAFEMs World Congr., Vancouver, BC, Canada.

[6] P. Moreau, F. Saint-Laurent, and J. B. Lister, "Drift free magnetic equilibrium reconstruction using neural network," Fusion Eng. Des., vol. 84, no. 7-11, pp. 1339-1343, Jun. 2009.

[7] G. Chitarin, R. S. Delogu, A. Gallo, and S. Peruzzo, "Technology developments for ITER in-vessel equilibrium magnetic sensors," Fusion Eng. Des., vol. 84, no. 2-6, pp. 593-598, Jun. 2009.

[8] J.-M. Moret, F. Buhlmann, D. Fasel, F. Hofmann, and G. Tonetti, "Magnetic measurements on the TCV tokamak," Rev. Sci. Instrum., vol. 69, no. 6, pp. 2333-2348, Jun. 1998.

[9] J.-M. Moret, F. Buhlmann, and G. Tonetti, "Fast single loop diamagnetic measurements on the TCV tokamak," Rev. Sci. Instrum., vol. 74, no. 11, p. 4634, Nov. 2003.

[10] A. J. Rogers, "Optical-fibre current measurement," Int. J. Optoelectron., vol. 3, no. 5, pp. 391-407, 1998.

[11] G. Chitarin, private communication, Jun. 2009.

[12] JET-EFDA Contributors, P. Sonato, W. R. Baker, P. Beaumont, C. Damiani, P. Fiorentin, A. Guigon, K. Fullard, A. Goodyear, L. Grando, S. Huntley, N. Lam, A. Lioure, A. Loving, D. Marcuzzi, S. Mills, S. Peruzzo, N. Pomaro, V. Riccardo, and M. Way, "Status of the halo current sensor project for JET-EP," Fusion Eng. Des., vol. 74, no. 1-4, pp. 757-761, Nov. 2005.

[13] ASDEX Upgrade Team, A. Kallenbach, A. Carlson, G. Pautasso, A. Peeters, U. Seidel, and H.-P. Zehrfeld, "Electric currents in the scrapeoff layer in ASDEX upgrade," J. Nucl. Mater., vol. 290-293, pp. 639-643, Mar. 2001.

[14] D. Testa, B. Schaller, J.-M. Moret, G. Vayakis, Y. Fournier, A. Encheva, H. Carfantan, M. Toussaint, R. Chavan, J.B. Lister, C. Walker, F. Sanchez, T. Maeder, G. Tonetti, A. Perez, and J. Guterl, "Baseline system design and prototyping for the ITER high-frequency magnetic diagnostic set," in Proc. 23rd SOFE Conf., San Diego, CA, Jun. 1-5, 2009, pp. 1-4.

[15] D. Testa, M. Toussaint, R. Chavan, F. Sanchez, A. Encheva, J. B. Lister, and J.-M. Moret, "Prototyping the ITER high frequency magnetic sensor using the conventional, Mirnov-type, pick-up coil," Fus. Sci. Technol., Jun. 2009, submitted for publication.

[16] D. Testa, Y. Fournier, T. Maeder, M. Toussaint, R. Chavan, J. Guterl, J. B. Lister, J.-M. Moret, B. Schaller, and G. Tonetti, "Prototyping the ITER high frequency magnetic sensor using the non-conventional LTCC technology," Fus. Sci. Technol., Jun. 2009, submitted for publication.
[17] D. Testa, H. Carfantan, R. Chavan, J. B. Lister, J.-M. Moret, and M. Toussaint, "Functional performance analysis and optimization for the high-frequency magnetic diagnostic system in ITER-Part 1: Overview of the results," Fus. Sci. Technol., Apr. 2010, accepted for publication.

[18] D. Testa, H. Carfantan, R. Chavan, J. B. Lister, J.-M. Moret, and M. Toussaint, "Functional performance analysis and optimization for the high-frequency magnetic diagnostic system in ITER-Part 2: Detailed overview of the analysis method and of the test calculations," Fus. Sci. Technol., Apr. 2010, accepted for publication.

[19] K. Kurihara and Y. Kawamata, "Development of a precise long-time digital integrator for magnetic measurements in a tokamak," in Proc. 17th IEEE/NPSS Symp. Fusion Eng., 1997, pp. 799-802.

[20] H.-J. Hartfuss, R. König, and A. Werner, "Diagnostics for steady state plasmas," Plasma Phys. Control. Fusion, vol. 48, no. 10, pp. R83-R150, Sep. 2006.

[21] A. Werner, "W7-X magnetic diagnostics: Performance of the digital integrator," Rev. Sci. Instrum., vol. 77, no. 10, p. 10E 307, Oct. 2006.

[22] C. Hennig, A. Werner, M. Marquardt, T. Bluhm, H. Kroiss, G. Kühner, P. Heimann, J. Maier, H. Riemann, and M. Zilker, "Continuous data acquisition with online analysis for the Wendelstein 7-X magnetic diagnostics," Fusion Eng. Des., vol. 83, no. 2/3, pp. 321-325, Apr. 2008.

[23] R. Van Nieuwenhove and L. Vermeeren, "Study of the radiation induced electromotive force effect on mineral insulated cables for magnetic diagnostics in ITER," Fusion Eng. Des., vol. 66-68, pp. 821-825, Sep. 2003.

[24] T. Nishitani, G. Vayakis, M. Yamauchi, T. Sugie, T. Kondoh, T. Shikama, E. Ishitsuka, and H. Kawashima, "Radiation-induced thermoelectric sensitivity in the mineral-insulated cable of magnetic diagnostic coils for ITER," J. Nucl. Mater., vol. 329-333, pt. 2, pp. 1461-1465, Aug. 2004, Proc. 11th Int. Conf. on Fusion Reactor Materials (ICFRM-11).

[25] R. Vila and E. Hodgson, "TIEMF in uniradiated $\mathrm{Cu}$ cored MI cables: Microstructure," Fusion Eng. Des., vol. 82, no. 5-14, pp. 1271-1276, Oct. 2007.

[26] R. Vila and E. Hodgson, "A TIEMF model and some implications for ITER magnetic diagnostic," Fusion Eng. Des., vol. 84, no. 7-11, pp. 1937-1940, Jun. 2009.

[27] G. Vayakis, T. Sugie, T. Kondoh, T. Nishitani, E. Ishitsuka, M. Yamauchi, H. Kawashima, and T. Shikama, "Radiation-induced thermoelectric sensitivity (RITES) in ITER prototype magnetic sensors," Rev. Sci. Instrum., vol. 75 , no. 10, p. 4324, Oct. 2004.

[28] J. Lister, R. Chavan, G. Chitarin, R. S. Delogu, A. Encheva, A. Gallo, E. R. Hodgson, L. C. Ingesson, A. Le-Luyer, P. Moreau, J.-M. Moret, S. Peruzzo, J. Roméro, D. S. Testa, M. Toussaint, G. Vayakis, and R. Vila, "The magnetics diagnostic set for ITER," Fusion Eng. Des., vol. 84, no. 2-6, pp. 295-299, Jun. 2009.

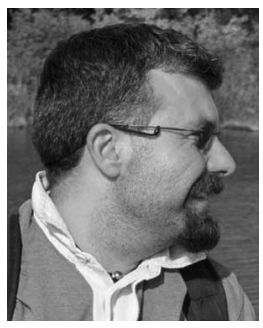

Duccio Testa was born in Torino, Italy, on May 8, 1970. He received the University degree in physics in Torino in 1994, the Master's degree in collective phenomena induced by high-energy relativistic electrons, and the $\mathrm{Ph} . \mathrm{D}$. degree in plasma physics from Imperial College London, London, U.K, in 1998.

After teaching in high school and being an archaeologist, he began his Ph.D. studies in October 1995, working on the interaction between fast ion and ion cyclotron range of frequencies and lower hybrid waves in JET. He held a postdoc position at MITPSFC, Boston, MS, from October 1998 to June 2002 and then at CRPP-EPFL, Lausanne, Switzerland from July 2002 to June 2005, in both cases though almost always working at JET on the Alfvén Eigenmodes Active Diagnostic System. Since June 2005, he has been a staff of the Centre de Research en Physique de Plasma, Lausanne, where he is currently works on the highfrequency magnetic diagnostic system for ITER and the Alfvén Eigenmodes Active Diagnostic system for JET.

Photographs and biographies of some of the authors not available at the time of publication. 